\title{
Evaluating the effect of the temporal intra-oral skeletal anchorage device (TISAD) for facilitating the anchorage reinforcement: A meta-analysis and systematic review
}

\author{
Ali Amiri**, Setareh Khosravi², Shiva Torabi ${ }^{3}$, Hadi Golshekan ${ }^{4}$, Fan Qi
}

\author{
'Department of Orthodontics, College of Stomatology, The First Affiliated Stomatological Hospital, Xi'an Jiaotong University, Xi'an 710004, PR China \\ ${ }^{2}$ Department of Orthodontics, School of Dentistry, Shahed University, Tehran, Iran \\ 'Department of Orthodontics, School of Dentistry, Shiraz University of Medical Sciences, Shiraz, Iran \\ ${ }^{4}$ Department of Oral and Maxillofacial Surgery, School of Dentistry, Guilan University of Medical Sciences, Rasht, Iran \\ ${ }^{*}$ Correspondence to: Ali Amiri (E-mail: draliamiri2020@gmail.com) \\ (Submitted: 04 January 2021 - Revised version received: 19 January 2021 - Accepted: 28 January 2021 - Published online: 26 February 2021)
}

\begin{abstract}
Objective In this meta-analysis and systematic review, we aimed to evaluate the effects of the temporal intra-oral skeletal anchorage devices (TISADs) to facilitates anchorage reinforcement.

Methods PubMed, Cochrane Library, Embase, ISI, Scopus, Web of Science, LILACS, BBO, OpenGrey, and Google Scholar, were used from the electronic databases until 2020 to perform systematic literature. Two reviewers extracted data blindly and independently from various abstracts as well as full texts of articles they considered for data extraction. Using the Cochrane collaboration's tool, we evaluated the publications' quality. Then, we computed the mean difference of TISADs and conventional anchorage groups with a confidence interval (Cl) of 95\%, restricted maximum likelihood, and random effect model of the mesial movement of molars and their tipping. Moreover, we employed Stata/MP 16 that has been considered the most rapid version of Stata for evaluating meta-analysis.

Results According to our electronic searches, 134 topics and abstracts with potential relevance were identified according to the research design. Finally, five publications matched the required inclusion criteria of the study. In addition, the Cochrane collaboration instrument exhibited all studies with low to moderate biases. Also, the mean difference of mesial molar movement showed less anchorage loss in the TISADs group vs. the controls, and a significant difference between these two groups ( $\mathrm{MD}=-1.74$ with a $\mathrm{Cl}$ of $95 \%,-2.76,-0.71$. $\mathrm{P}=0.00$ ). Conclusions TISADs can reduce treatment time, and TISADs are more effective in enabling the anchorage than other methods and higher tipping in the TISADs.

Keywords Implant-supported, Dental implants, Molar movement, Meta-analysis.
\end{abstract}

\section{Introduction}

The main element of anchorage control is proposed to be resistance to the adverse movement of maxillary mesial molar when the maxillary arch spaces close, which can improve the treatment results. ${ }^{1-3}$ In a person with full class II malocclusion, treatment is successful when the extraction spaces are entirely closed from the front with different methods and with maximum anchorage. ${ }^{4-6}$ Extraoral appliances can seem useful in anchorage control, but it depends on the individual's adaptation and anchorage control. Isolated cases of facial injury should also be associated with the patient. ${ }^{7}$ The effectiveness of intra-oral appliances such as the arch of nance holding, transpalatal bar is still in question and can be answered with prospective studies and treatment planning. ${ }^{8,9}$ According to a study in the field, temporal intra-oral skeletal anchorage devices (TISADs), which are called mini-implant or miniscrews, have been developed as the little titanium screws embedded in palatal or vestibular mucosa across the bone for creating an individual inflexible anchor unit.

Furthermore, TISADs are capable of connecting to the adjacent tooth for reinforcing anchorage. ${ }^{10}$ TISADs can be a conventional option that, unlike older methods, is noncompliant. TISADs do not attach directly to the teeth and are considered simple, differing from other methods. According to studies, the survival rate of TISADs was between 80 and 94\%. ${ }^{10-12}$ Therefore, it can be used as a potential method to require an anchorage reinforcement in the treatment process.
The evidence review also shows discrepancies in TISADs' efficiency $v s$. traditional approaches to anchorage supplementation. ${ }^{13-18}$ Becker et al.s meta-analysis and systematic review answered this question: "How do the orthodontic mini-implants perform for the quality of anchorage quality in comparison to the traditional devices in cases which require en-masse retractions of the upper front teeth?" and the answer was orthodontic mini-implants can achieve maximum anchorage en-masse retraction and direct anchorage. ${ }^{16}$ Due to the discrepancy in the results and reaching an overall conclusion, anchorage reinforcement is facilitated by our meta-analysis study and systematic review aimed to assess the effects of TISADs on conventional comparison anchorage in the maxillary arch.

\section{Method}

\section{Search strategy}

PubMed, Cochrane Library, Embase, ISI, Scopus, Web of Science, LILACS, BBO, OpenGrey, and Google Scholar, were used from the electronic databases until 2020 to perform systematic literature. Therefore, for managing electronic titles, a software program (Endnote X8) was used. With mesh terms, searches were performed:

("Implant-Supported"[Mesh], Dental Prosthesis, OR "Prosthesesand Implants"[Mesh] OR "DentalImplants"[Mesh], OR "micro-implant” [Mesh], OR "mini-screw” [Mesh], OR 
"temporary anchorage device" [Mesh] OR "temporary intraoral skeletal anchorage devices" [Mesh] OR "miniplates" [Mesh] AND "orthodontics" [Mesh]) and keywords dental prosthesis, prostheses, implants, micro-implant, temporary intra-oral skeletal anchorage devices, anchorage reinforcement, miniplates, implant-supported, orthodontics were used for other databases.

With regard to the core criterion of PRISMA, we carried out our present systematic review and meta-analysis ${ }^{19}$ and PICO strategy.

\section{Inclusion criteria}

1. The randomized-controlled trials (RCTs), prospective and retrospective cohort investigations as well as controlled clinical trials.

2. Anchorage in the maxillary arch.

3. Intervention (TISADs) and Comparison group (conventional anchorage).

4. Change of Mesial molar movement and tipping of molars.

5. English language.

\section{Exclusion criteria}

1. Case reports and studies, reviews, in-vitro studies, non-control group animals.

2. Studies incomplete or inconsistent data for the purpose of the present study.

\section{Data extraction and quality assessment}

Two reviewers extracted data blindly and independently from abstracts as well as full texts of the publications for data extraction. In case of disagreement, the third referee examined or confirmed the opinions of the two referees. The study's data, years, study design, number of patients, mean/range of age, force, diameter, and length of TISADs, mean of treatment duration were extracted from the study, mean of treatment duration, the diameter of TISADs, length of TISADs, sample size, mean/ range of age. With the use of Cochrane Collaboration's instrument, the quality of the studies included was evaluated. ${ }^{20}$ Finally, the scale score for low and high and unclear risks was 1 and 0 , respectively. This score ranges between 0 and 6 , and the greater quality results from the greater score.

\section{Meta-analysis}

In this step, the mean difference of the TISADs and conventional anchorage group with a confidence interval (CI) of 95\%, restricted maximum likelihood, and random effect model of the molars' mesial movement and their tipping were calculated. RCT studies were statistically evaluated by analyzing the subgroup and establishing significance by $\mathrm{P}<0.05$, both jointly and separately. To deal with potential heterogeneity, random effects were used, showing I2 heterogeneous cases. Ultimately, forest plots and meta-analysis were assessed through software Stata16. A P-value below 0.05 is statistically significant (typically 0.05 ).

\section{Results}

In the related searches, 134 topics and abstracts with potential relevance were found. We excluded 95 publications from our study due to incompatibility with our inclusion criteria in the abstract. Therefore, in the next stage, the full-text papers from 36 studies have been thoroughly reviewed, so we excluded 31 investigations because of incompatibility with our inclusion criteria. In this way, five investigations matched the required inclusion criteria (Fig. 1). In this meta-analysis, Table 2 gives each study.

\section{Study characteristics}

Therefore, we considered five investigations of the RCTs. As mentioned earlier, cases in TISADs groups and control group were 125 and 149, respectively; a total was 274; the mean age
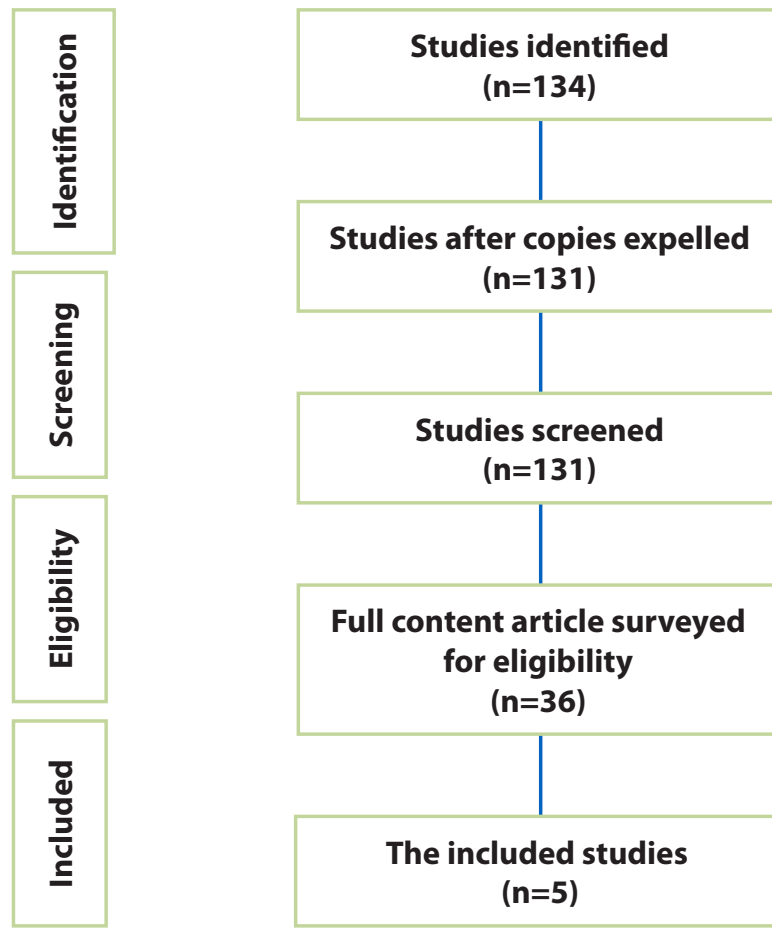

\section{Studies excluded $(n=95)$}

In-vitro studies, case reports, case studies, reviews, non-control group animal.

Not meet eligibility criteria in the abstract.

\section{Full content article excluded $(n=31)$}

Studies incomplete or inconsistent data for the purpose of the present study. Not meet eligibility criteria in full text.

Fig. 1 Study attrition. 


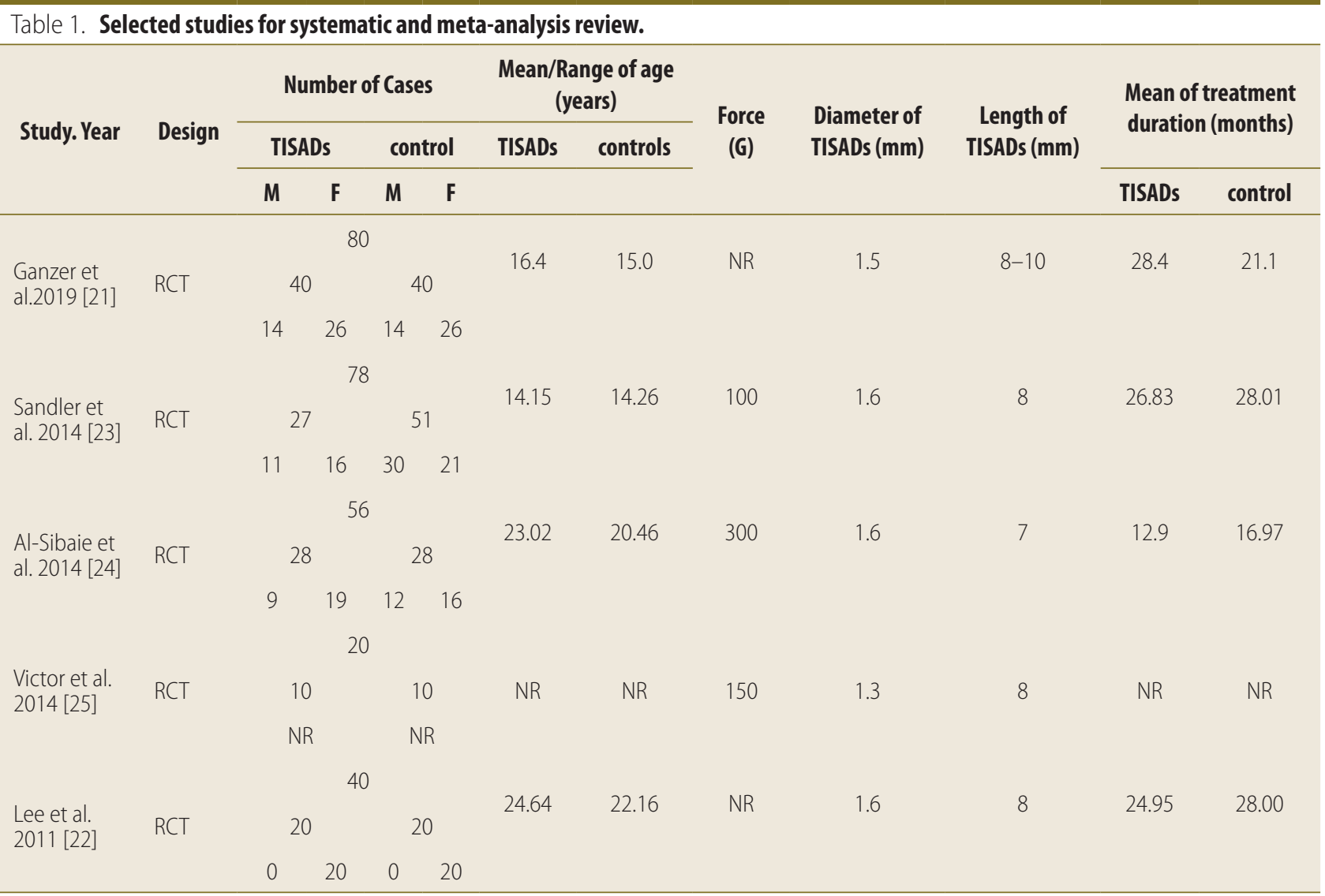

RCT: a randomized controlled trial. TISADs: temporary intra-oral skeletal anchorage devices. M: male. F: female. NR: Not reported.

in TISADs groups was 21.58 years according to the mean age of studies included (Table1). The magnitude of the force in two studies ${ }^{21,22}$ was not reported; one study ${ }^{23}$ used 100G and Al-Sibaie et al. ${ }^{24} 300 \mathrm{G}$, another study ${ }^{25} 150 \mathrm{G}$. The diameter of TISADs was $1.3,1.5$, and $1.6 \mathrm{~mm}$. Also, the length of TISADs was $7-10 \mathrm{~mm}$. The mean treatment duration in TISADs groups and the control group was 21.27 and 26.52 months, respectively. One study did not report treatment duration ${ }^{25}$ (Table 2).

\section{Evaluation of bias}

Based on the Cochrane Collaboration's instrument, three investigations acquired a 5/6 total score, one study had a 4/6 overall score, and one study had a $2 / 6$ overall score. In all studies, except Victor et al. 2014, this finding indicated a low to moderate risk of bias ${ }^{25}$ (Table 2 ). As a result, the quality of the studies was high.

\section{Mesial molar movement}

Mean difference was ( $\mathrm{MD}=-1.74$ with a CI of $95 \%,-2.76$, -0.71. $\mathrm{P}=0.00)$ among three studies $\left(\mathrm{I}^{2}=0.00 \% ; \mathrm{P}=0.55\right)$ and heterogeneity identified. In the group of TISADs vs. the control group, anchorage loss was significantly less. We did not observe any significant differences ws found $(\mathrm{P}=0.55)$ between the studies (Fig. 2).

\begin{tabular}{|c|c|c|c|c|c|c|c|}
\hline Study & $\begin{array}{l}\text { Random } \\
\text { generation of } \\
\text { sequences }\end{array}$ & $\begin{array}{l}\text { Concealment } \\
\text { of Allocation }\end{array}$ & $\begin{array}{l}\text { Participants } \\
\text { and personnel } \\
\text { blinding }\end{array}$ & $\begin{array}{l}\text { Blinding of } \\
\text { outcomes } \\
\text { evaluation }\end{array}$ & $\begin{array}{l}\text { Insufficient } \\
\text { data on } \\
\text { outcomes }\end{array}$ & $\begin{array}{l}\text { Selective } \\
\text { reporting }\end{array}$ & Total score \\
\hline Ganzer et al.2019 [21] & $\odot$ & $\odot$ & + & $\oplus$ & $\oplus$ & (?) & 5 \\
\hline Sandler et al.2014 [23] & $\odot$ & $\odot$ & & & & $\odot$ & 5 \\
\hline Al-Sibaie et al.2014 [24] & $\odot$ & $\odot$ & & & $\odot$ & $\oplus$ & 5 \\
\hline Victor et al.2014 [25] & ?? & (?) & & (?) & $\oplus$ & $\oplus$ & 2 \\
\hline Lee et al.2011 [22] & $\odot$ & $\odot$ & & $\odot$ & $\odot$ & (?) & 4 \\
\hline
\end{tabular}

Low (+), unclear (?), high (-). 


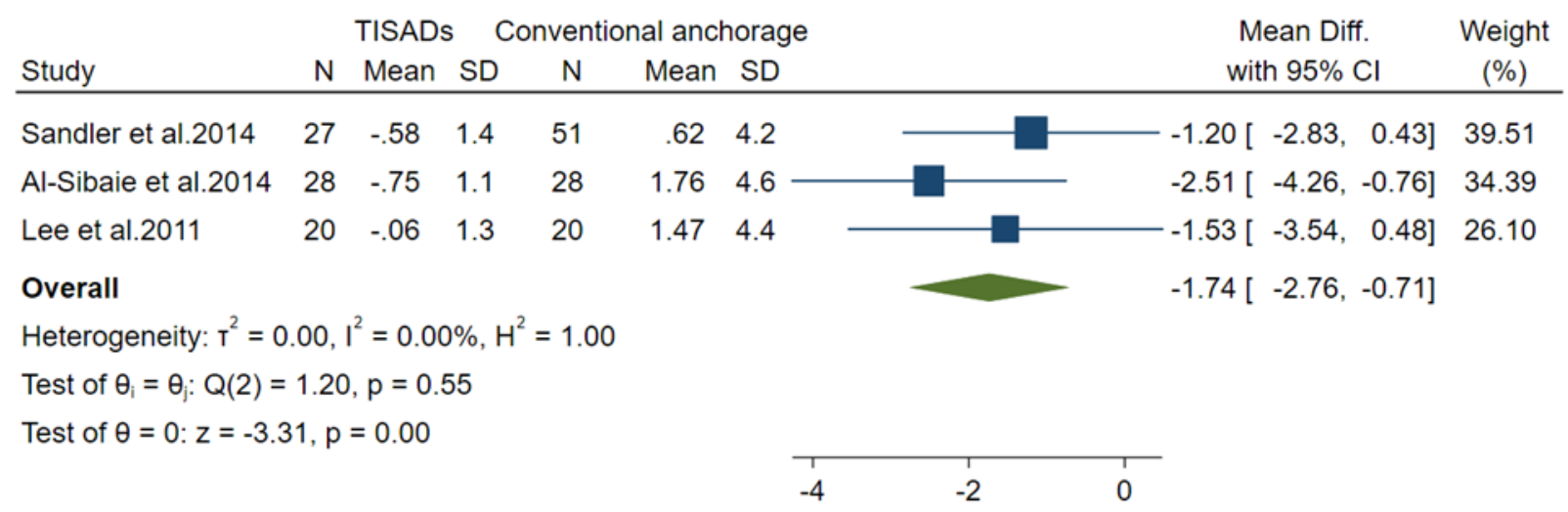

Random-effects REML model

Fig. 2 Mesial molar movement outcomes in TISADs group and conventional anchorage.

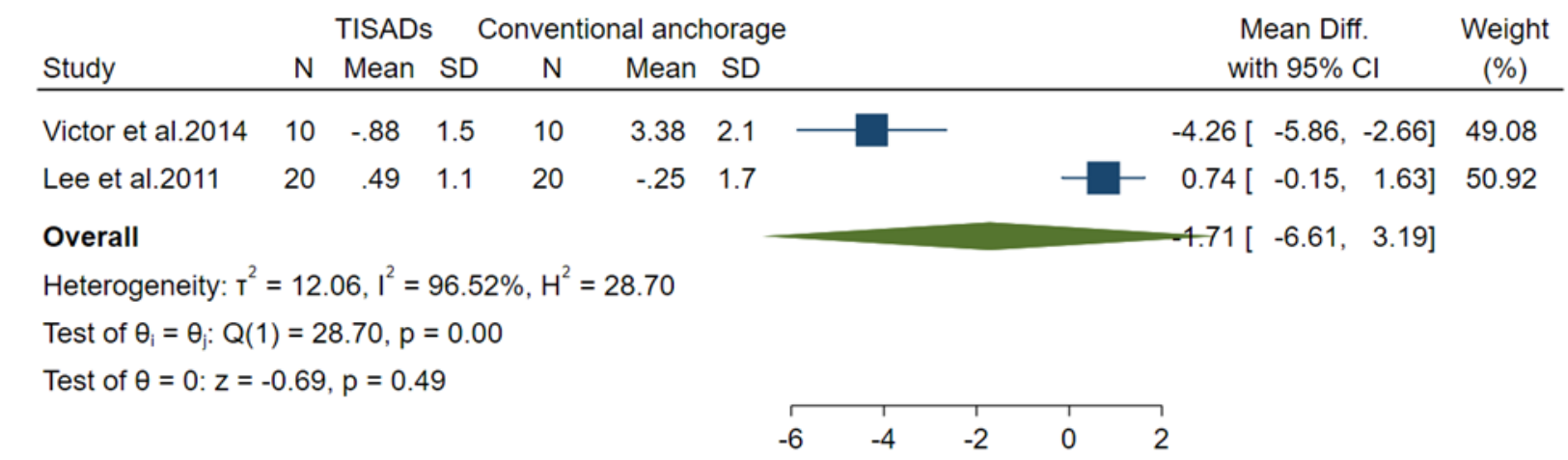

Random-effects REML model

Fig. 3 Tipping of molars outcomes in TISADs group and conventional anchorage.

\section{Tipping of molars}

Mean difference was (MD, -1.71 95\% CI -6.61, 3.19. $\mathrm{P}=0.48)$, two studies have found heterogeneity ( $\mathrm{I} 2=96.52 \%$; $\mathrm{P}=0.00$ ). More tipping in the TISADs group was shown in Fig. 3, but the difference between the TISADs and the control group was not statistically significant.

\section{Discussion}

We put TISADs in palatal or vestibular mucosae across the bone to create an individual inflexible anchor unit. As mentioned earlier, we evaluated the effects of TISADs in the maxillary arch in this meta-analysis and systematic review. Our finds indicate that in the TISADs group vs. the control group, anchorage loss was significantly less. More tipping was observed in the TISADs group. The anchorage must be maintained by eliminating undesired mesial molar movement for a better choice in treatment strategy. Before using TISADs, the headgear, Nance support arch, and transpalatal bar were reinforced in the anchorage, but the anchorage may be destroyed again..$^{26-28}$

In accordance with the present study results, distal movement of molar and anchorage increase is also observed for TISADs. ${ }^{16,29}$ These results can be estimated from the friction in the molar between the archwire and the bracket slot; it can also depend on the size of the archwire. Generally, the results of this study indicate that TISADs are better for anchorage preservation than other conventional methods.

On the other hand, according to the outputs of the present study, we did not find any significant differences between TISADs and the controls in the molars' tilting. Still, according to Fig. 3, it can be seen that distal tipping of the molar in the TISADs group compared to other methods, the usual ones were more consistent. Also, the duration of treatment was mentioned, which was approximately 4 months less in TISADs in comparison to the controls. Other studies have confirmed these results, ${ }^{2,7,21,30}$ which means that using TISADs will also reduce the duration of treatment. According to the selected studies in the present study, data were insufficient for meta-analysis to examine changes in the vertical molar position.

The limitations of the current study include the limited numbers of clinical trials addressing the application of the TISADs and almost more studies focused on typically cephalometric outcomes. As a result of newer studies with high and adequate sample size, the study of all variables and the duration of treatment is needed, also; due to the limited RCT studies in the use of TISADs; it is better to do more RCT studies with high quality and low risk of bias in this area. However, patient-centered outcomes are incorporated and focused on technical outcome measures, incorporating relevant results for both patients and clinicians. We assume these research findings will be of great help for future dental research. 


\section{Conclusion}

TISADs could reduce treatment time, more tipping, and more effectively enable the anchorage than conventional methods. Recommended in the future, high-quality studies on this aim must be done for a more comprehensive and better conclusion.

\section{Conflict of Interest}

None

\section{References}

1. Lai EH, Yao CC, Chang JZ, Chen I, Chen YJ. Three-dimensional dental model analysis of treatment outcomes for protrusive maxillary dentition: comparison of headgear, miniscrew, and miniplate skeletal anchorage. Am J Orthodont Dentofacial Orthoped. 2008;134(5):636-45. https://doi. org/10.1016/j.ajodo.2007.05.017.

2. Park CO, Sa'aed NL, Bayome M, Park JH, Kook YA, Park YS, Han SH. Comparison of treatment effects between the modified C-palatal plate and cervical pull headgear for total arch distalization in adults. Korean J Orthodont. 2017;47(6):375-83. https://doi.org/10.4041/kjod.2017.47.6.375.

3. Melsen B, Bosch C. Different approaches to anchorage: a survey and an evaluation. Angle Orthodont. 1997;67(1):23-30. https://doi. org/10.1043/0003-3219(1997)067<0023:DATAAS>2.3.CO;2.

4. Wahl N. Orthodontics in 3 millennia. Chapter 15: Skeletal anchorage. Am J Orthodont Dentofacial Orthoped. 2008;134(5):707-10. https://doi. org/10.1016/j.ajodo.2008.04.015.

5. Alharbi F, Almuzian M, Bearn D. Anchorage effectiveness of orthodontic miniscrews compared to headgear and transpalatal arches: a systematic review and meta-analysis. Acta Odontol Scand. 2019;77(2):88-98. https:// doi.org/10.1080/00016357.2018.1508742.

6. Kyung HM. Progress of anchorage in lingual orthodontic treatment. Temp Anchor Devices Clin Orthodont. 2020:489-96. https://doi. org/10.1002/9781119513636.ch47.

7. Antoszewska-Smith J, Sarul M, Łyczek J, Konopka T, Kawala B. Effectiveness of orthodontic miniscrew implants in anchorage reinforcement during enmasse retraction: A systematic review and meta-analysis. Am J Orthodont Dentofacial Orthoped. 2017;151(3):440-55.https://doi.org/10.1016/j. ajodo.2016.08.029

8. Diar-Bakirly S, Feres MF, Saltaji H, Flores-Mir C, El-Bialy T. Effectiveness of the transpalatal arch in controlling orthodontic anchorage in maxillary premolar extraction cases: A systematic review and meta-analysis. Angle Orthodont. 2017;87(1):147-58. https://doi.org/10.2319/021216-120.1

9. Feldmann I, Bondemark L. Orthodontic anchorage: a systematic review. The angle orthodontist. 2006 May;76(3):493-501. https://doi.org/10.1043/00033219(2006)076[0493:OA]2.0.CO;2.

10. Kuroda S, Sugawara Y, Deguchi T, Kyung HM, Takano-Yamamoto T. Clinical use of miniscrew implants as orthodontic anchorage: success rates and postoperative discomfort. Am J Orthodont Dentofacial Orthoped. 2007;131(1):9-15. https://doi.org/10.1016/j.ajodo.2005.02.032.

11. Jing Z, Wu Y, Jiang W, Zhao L, Jing D, Zhang N, Cao X, Xu Z, Zhao Z. Factors affecting the clinical success rate of miniscrew implants for orthodontic treatment. Int J Oral Maxillofac Implants. 2016;31(4):835-841.

12. Antoszewska J, Papadopoulos MA, Park HS, Ludwig B. Five-year experience with orthodontic miniscrew implants: a retrospective investigation of factors influencing success rates. Am J Orthodont Dentofacial Orthoped. 2009;136(2):158-e1.https://doi.org/10.1016/j.ajodo.2009.03.032.

13. Barthélemi S, Desoutter A, Souaré F, Cuisinier F. Effectiveness of anchorage with temporary anchorage devices during anterior maxillary tooth retraction: A randomized clinical trial. Kor J Orthodont. 2019;49(5):279-85. https://doi.org/10.4041/kjod.2019.49.5.279.

14. Benson PE, Tinsley D, O'Dwyer JJ, Majumdar A, Doyle P, Sandler PJ. Midpalatal implants vs headgear for orthodontic anchorage-a randomized clinical trial: cephalometric results. Am J Orthodont Dentofacial Orthoped. 2007;132(5):606-15.https://doi.org/10.1016/j.ajodo.2006.01.040.

15. Sandler J, Benson PE, Doyle P, Majumder A, O'Dwyer J, Speight P, Thiruvenkatachari B, Tinsley D. Palatal implants are a good conventional to headgear: a randomized trial. Am J Orthodont Dentofacial Orthoped. 2008;133(1):51-7. https://doi.org/10.1016/j.ajodo.2007.04.032.

16. Becker K, Pliska A, Busch C, Wilmes B, Wolf M, Drescher D. Efficacy of orthodontic mini implants for en masse retraction in the maxilla: a systematic review and meta-analysis. Int J Implant Dentist. 2018;4(1):35.DO| 10.1186/s40729-018-0144-4
17. Khlef HN, Hajeer MY, Ajaj MA, Heshmeh O. Evaluation of treatment outcomes of en masse retraction with temporary skeletal anchorage devices in comparison with two-step retraction with conventional anchorage in patients with dentoalveolar protrusion: A systematic review and meta-analysis. Contemp Clin Dentist. 2018;9(4):513-523. doi:10.4103/ ccd.ccd_661_18.

18. Upadhyay M, Yadav S, Patil S. Mini-implant anchorage for en-masse retraction of maxillary anterior teeth: a clinical cephalometric study. Am J Orthodont Dentofacial Orthoped. 2008;134(6):803-10. https://doi. org/10.1016/j.ajodo.2006.10.025.

19. Moher D, Liberati A, Tetzlaff J, Altman DG, Altman D, Antes G, Atkins D, Barbour V, Barrowman N, Berlin JA, Clark J. Preferred reporting items for systematic reviews and meta-analyses: The PRISMA statement (Chinese edition). J Chin Integr Med. 2009;7(9):889-96. https://doi.org/10.1371/ journal.pmed.1000097

20. Higgins JP, Altman DG, Gøtzsche PC, Jüni P, Moher D, Oxman AD, Savović J, Schulz KF, Weeks L, Sterne JA. The Cochrane Collaboration's tool for assessing risk of bias in randomised trials. Bmj. 2011;343:d5928.

21. Ganzer N, Feldmann I, Petrén S, Bondemark L. A cost-effectiveness analysis of anchorage reinforcement with miniscrews and molar blocks in adolescents: a randomized controlled trial. Eur J Orthodont. 2019;41(2):1807. https://doi.org/10.1093/ejo/cjy041.

22. Lee $\mathrm{AY}$, Kim YH. Comparison of movement of the upper dentition according to anchorage method: orthodontic mini-implant versus conventional anchorage reinforcement in Class I malocclusion. ISRN dentistry. 2011 https://doi.org/10.5402/2011/321206.

23. Sandler J, Murray A, Thiruvenkatachari B, Gutierrez R, Speight P, O'Brien $K$. Effectiveness of 3 methods of anchorage reinforcement for maximum anchorage in adolescents: a 3-arm multicenter randomized clinical trial. Am J Orthodont Dentofacial Orthoped. 2014;146(1):10-20. https://doi. org/10.1016/j.ajodo.2014.03.020

24. Al-Sibaie S, Hajeer MY. Assessment of changes following en-masse retraction with mini-implants anchorage compared to two-step retraction with conventional anchorage in patients with class $\|$ division 1 malocclusion: a randomized controlled trial. Eur J Orthodont. 2014;36(3):275-83. https://doi.org/10.1093/ejo/cjt046.

25. Victor D, Prabhakar R, Karthikeyan MK, Saravanan R, Vanathi P, Vikram NR, Reddy PA, Sudeepthi M. Effectiveness of mini implants in three-dimensional control during retraction-a clinical study. Journal of clinical and diagnostic research: JCDR. 2014;8(2):227-232. doi:10.7860/JCDR/2013/7801.4066.

26. Geron S, Shpack N, Kandos S, Davidovitch M, Vardimon AD. Anchorage loss - a multifactorial response. Angle Orthodont. 2003;73(6):730-737. https://doi.org/10.1043/0003-3219(2003)073<0730:ALMR>2.0.CO;2.

27. Dodeja T, Bhat SR, Talwar A. A comparative study to evaluate the effectiveness of lateral cephalogram and study cast to measure anteroposterior anchorage loss with preadjusted edgewise appliance. Ind J Orthodont Dentofacial Res. 2018;4(3):156-60. DOI: 10.18231/24556785.2018.0030.

28. Dai FF, Xu TM, Shu G. Comparison of achieved and predicted tooth movement of maxillary first molars and central incisors: First premolar extraction treatment with Invisalign. Angle Orthodont. 2019;89(5):679-87. https://doi.org/10.2319/090418-646.1

29. Upadhyay M, Yadav S, Nagaraj K, Patil S. Treatment effects of mini-implants for en-masse retraction of anterior teeth in bialveolar dental protrusion patients: a randomized controlled trial. Am J Orthodont Dentofacial Orthoped. 2008;134(1):18-29. https://doi.org/10.1016/j.ajodo.2007.03.025.

30. Park HS, Yoon DY, Park CS, Jeoung SH. Treatment effects and anchorage potential of sliding mechanics with titanium screws compared with the Tweed-Merrifield technique. Am J Orthodont Dentofacial Orthoped. 2008;133(4):593-600. https://doi.org/10.1016/j.ajodo.2006.02.041

This work is licensed under a Creative Commons Attribution-NonCommercial 3.0 Unported License which allows users to read, copy, distribute and make derivative works for non-commercial purposes from the material, as long as the author of the original work is cited properly. 